\title{
Eyes on New Product Development
}

\author{
Gary D. Novack
}

$\mathbf{I}_{\mathrm{tios}}^{\mathrm{N}}$ N THE RECENT PERIOD, preclinical research and collaborations in ocular infections and retinal diseases have been announced, two pharmaceutical manufacturers are joining forces, and European approvals have been obtained for retina products. In addition, a novel fixed-dose combination for the maintenance of intraoperative mydriasis, has been submitted for U.S. and European approval. Sterility continues to be an issue with ophthalmic products at compounding pharmacies.

\section{Ophthalmic Pharmaceuticals}

- Adamis Pharmaceuticals Corporation is evaluating its antimicrobial and spermicidal agent, C31G, in a preclinical model of ocular keratitis (September 2013).

- Akorn, Inc. will acquire Hi-Tech Pharmacal Co., Inc. (August 2013).

- Alcon announced that the National Institute for Health and Care Excellence (NICE) Appraisal Committee has delivered a positive Final Appraisal Determination (FAD) for Jetrea ${ }^{\circledR}$, recommending its use to treat adults with vitreomacular traction, including macular hole (August 2013).

- Bayer HealthCare announced that Eylea ${ }^{\circledR}$ (aflibercept solution for injection) has been approved by the European Commission for the treatment of visual impairment due to macular edema secondary to central retinal vein occlusion (September 2013).

- Omeros Corporation submitted a New Drug Application to the U.S. Food and Drug Administration (FDA) and a Marketing Authorization Application (MAA) to the European Medicines Agency (EMA) seeking approval to market OMS302 for use in patients undergoing intraocular lens replacement surgery. OMS302 is a combination of phenylephrine and ketorolac to maintain intraoperative mydriasis (August and September 2013).

- ThromboGenics NV entered into a collaboration and license agreement with Bicycle Therapeutics to develop and commercialize novel drugs inhibiting a specific target for the treatment of ophthalmic diseases, such as diabetic macular edema. (September 2013).

\section{Other Ophthalmic Products}

- ArcticDx, Inc. is launching a pharmacogenetic analysis of CFH and ARMS2 genetic polymorphisms to predict the response to eye vitamin therapies for patients suffering from age-related macular degeneration (August 2013).

\section{Regulatory, Government, and Pharmaceutical Industry}

- Allergan received FDA approval for Botox Cosmetic ${ }^{\circledR}$ (onabotulinumtoxinA) for the temporary improvement in the appearance of moderate to severe lateral canthal lines, known as crow's feet, in adults (September 2013).

- Galderma announced that the U.S. FDA approved Mirvaso $^{\circledR}$ (brimonidine topical gel $0.33 \%$ ) to treat facial redness in adult rosacea patients (August 2013).

- The U.S. FDA announced recalls of several ophthalmic products related to either sterility issues, or issues related to quality at an independent, third-party laboratory. Products involved include the carboxymethylcellulose sodium ophthalmic solution and bevacizumab (extemporaneous formulation, September 2013).

\section{Author Disclosure Statement}

The author consults for numerous ophthalmic pharmaceutical, and medical device firms.

Received: September 19, 2013

Accepted: September 30, 2013

Address correspondence to: Dr. Gary D. Novack PharmaLogic Development, Inc. 17 Bridgegate Drive San Rafael, CA 94903

E-mail: gary_novack@pharmalogic.com 